\title{
UNILATERAL HIGH BIFURCATION OF BRACHIAL ARTERY: A CASE REPORT
}

\author{
Ahmed M. Auwal, Adaudu D. Zagga, Samuel A. Asala \\ Correspondence: Department of Anatomy, Faculty of Basic Medical Sciences, College of Health \\ sciences, Usmanu Danfodiyo University, Sokoto, Nigeria. Tel.: +2348039438289, E-mail: \\ auwal.ahmedmusa@udusok.edu.ng
}

\begin{abstract}
The Brachial artery usually begins as the continuation of the Axillary Artery at the inferior border of the Teres Major muscle and terminates by bifurcating into radial and ulnar arteries in the cubital fossa. A case of unilateral bifurcation of the artery $7.5 \mathrm{~cm}$ distal to the inferior border of the Teres Major muscle in the proximal half of the right arm was identified in a northern Nigerian cadaver that was dissected by medical students of Usmanu Danfodiyo University, Sokoto. The Profunda Brachii, Superior Ulnar Collateral and Inferior Ulnar Collateral arteries arose from the relatively short brachial arterial trunk. Although the documented incidence of this anatomical variation is low in Nigeria, its concomitant widespread documentation in other parts of the world makes it a sufficiently important anatomical variation of the Brachial Artery, to warrant its being taught to students of Anatomy and Medicine. The knowledge of anatomical variations of the brachial artery and its branches is also important in radiological and clinical practice.
\end{abstract}

Keywords: Anatomical variation, brachial, artery, Nigeria

\section{INTRODUCTION}

The Brachial Artery is the main artery of the arm. It usually begins as a continuation of the Axillary Artery at the distal border of the tendon of Teres Major Muscle and ends about a centimeter distal to the elbow joint (at the level of the neck of the radius) by dividing into Radial and Ulnar Arteries (Johnson et al, 2005). Occasionally the artery divides proximally into two trunks, which may reunite. Frequently it divides more proximally than usual and this unusually short segment of the Brachial Artery may bifurcate into the usual Radial and Ulnar Arteries or it may trifurcate to include the Common Interosseous Artery (Johnson et al, 2005). High level bifurcation of the Brachial Artery is not an uncommon anatomical finding. Bifurcation of the artery at levels other than in the cubital fossa have been documented as case reports from Nigeria (Okoro and Chiburum, 2003), Serbia (Krstonosic et al,
2010), Nepal (Satyanarayana et al, 2010), India (Shewale et al, 2012; Pokhrel and Bhatnagar, 2013) and Brazil (Jacomo et al, 2014). A few studies in cadavers (Varlekar et al, 2013; Pundge et al, 2014) and in patients undergoing ultrasound preoperative vascular mapping (Kian et al, 2012) have reported the incidence of high branching of Brachial Artery.

The Brachial Artery, which initially lies lateral to the Median Nerve proximally, crosses obliquely anterior to it at about the middle of the arm and lies on its medial side distally. The Ulnar Nerve is posterior to the artery proximally, leaves it in the lower part of the arm and passes posteriorly through the medial intermuscular septum. The artery is superficial in its course in the arm, lying immediately deep to the deep fascia of the anteromedial aspect of the arm. It passes deeply into the cubital fossa

Submitted $7^{\text {th }}$ October November 2016, accepted May 2017. Auwal AM, Zagga AD, Asala SA. Unilateral high bifurcation of brachial artery. Anatomy Journal of Africa. 2017. Vol 6 (2): $916-918$ 
where it divides into the Radial and Ulnar Arteries, usually at the level of the neck of the radius (Johnson et al, 2005).
In the following report, a unilateral case of high bifurcation of the Brachial Artery in the right upper limb of a Nigerian is presented.

\section{CASE REPORT}

The right upper limb of a northern Nigerian male adult cadaver, previously fixed in formalin for routine dissection by undergraduate medical students in the Department of Anatomy, Faculty of Basic Medical Sciences, Usmanu Dan Fodiyo University, Sokoto, Nigeria, was the subject of this report. The age and cause of death of the study case were not known. A Brachial Artery which bifurcated in the proximal half of the arm at a point $7.5 \mathrm{~cm}$ distal to the lower border of the Teres Major Muscle, was observed (Fig 1). The artery, however, bifurcated into the usual Radial and Ulnar arteries, both of which were of similar calibre. The short trunk of the artery gave rise to the Profunda Brachii, Superior Ulnar Collateral and Inferior Ulnar Collateral arteries before its bifurcation. The Median Nerve passed deep to the Radial Artery in its course to the medial side of the arm. As it approached the Ulnar Artery, the nerve crossed superficial to it to reach the medial side of the arm. The Radial Recurrent Artery arose normally from the Radial Artery. The Common Interosseous and the anterior and posterior Ulnar Recurrent Arteries also arose normally from the Ulnar Artery. There was no similar arterial variation in the left arm.

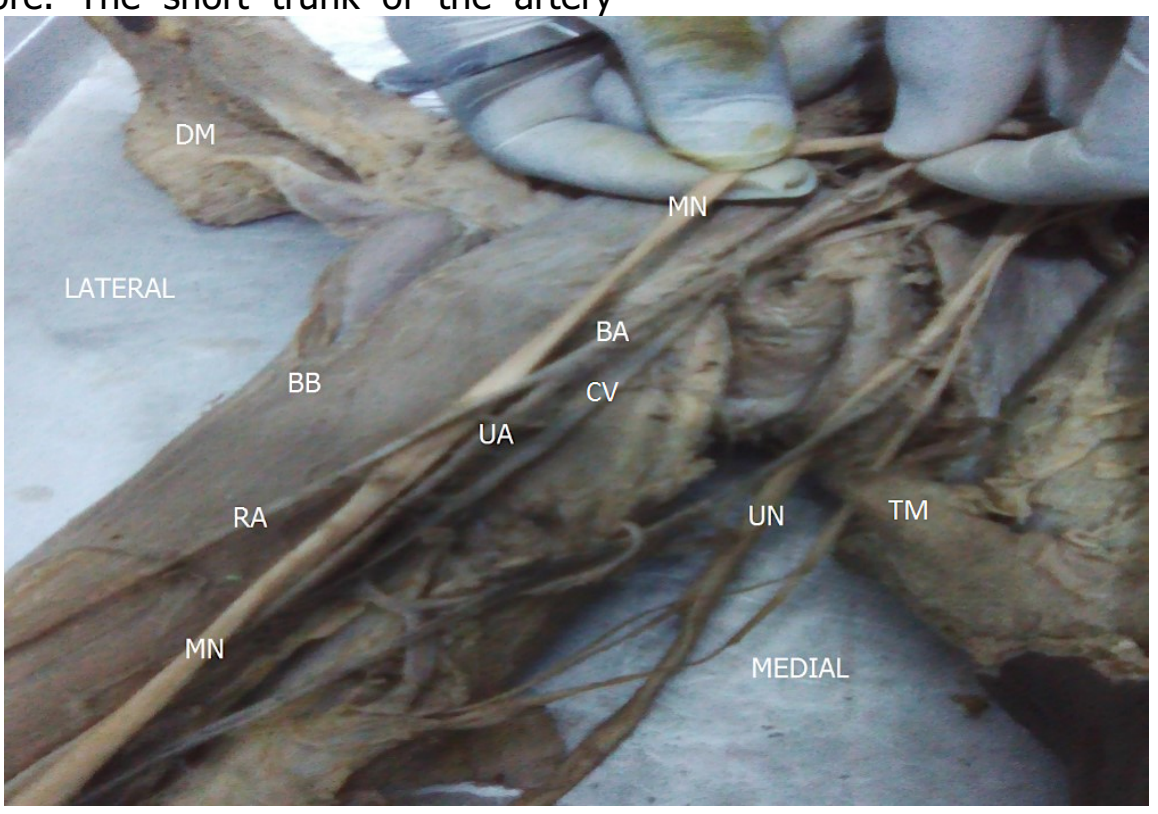

Figure 1: illustrates Brachial Artery (BA) dividing into Radial Artery (RA) and Ulnar artery (UA) at the level of union of the two heads of the Biceps Brachii Muscle (BB). Brachial and Radial arteries are lying superficially in the arm. BA - Brachial Artery, RA - Radial Artery, UA - Ulnar Artery, MN - Median Nerve, UN - Ulnar Nerve, CV - Cephalic Vein, BB - Biceps Brachii Muscle, DM - Deltoid Muscle, TM - Teres Major Muscle.

\section{DISCUSSION}

A high bifurcation of the Brachial Artery in the proximal half of the arm similar to the finding in southern Nigeria, but which was reported as aberrant Radial Artery (Okoro and Chiburum, 2003), is now being reported in northern Nigeria. This report has therefore added to the
Nigerian data of variations in vascular anatomy of the upper limb in Nigerians.

The present report is in agreement with many others in which cases of high bifurcation of Brachial Artery were present unilaterally with no consistent right or left dominance (Kian et al, 
2012; Pundge et al, 2014). A study that compares the side of occurrence of this anatomical variation with lateralization of upper limb use may attempt to show possible correlation between $\operatorname{limb}$ function and the vascular anatomical variation. The major obstacle to this type of study, however, is nonavailability of personal data of our cadavers.

From our reported case and some others (Krstonosic et al, 2010; Satyanarayana et al, 2010), it appears that the Brachial Artery usually gives rise to all of its branches regardless of its point of bifurcation. The benefit of this finding is that a surgeon who deliberately searches for and identifies the branches of the Brachial Artery is unlikely to injure or ligate them in error.

In the case that we reported, the Radial and Ulnar Arteries ran superficially from the point of their formation to the cubital fossa. This position is in line with that reported by Krstonosic et al, (2010) and portends danger to the arteries in injuries of the arm. Their unexpected position may also be confusing to the clinicians during surgery or cannulation procedures. The brachial pulse that is usually palpable along the entire medial border of the Biceps Brachii Muscle may be absent or weak and therefore, difficult to feel.

Therefore, with a reported incidence of high bifurcation of the Brachial Artery in the arm of up to $12 \%$ (Kian et al, 2012; Varlekar et al, 2013; Pundge et al, 2014), the existence of the vascular variation and the associated radiological and clinical implications of it should be taught to students of Anatomy and Medicine.

\section{REFERENCES}

1. Jacomo AL, Martinez CAR, Saleh SO, Andrade M, Akamatsu FE. 2014. A rare pattern of brachial artery variation: Case report. Int J Morphol. 32:542-545.

2. Johnson D, Ellis H, Collins P. 2005. Upper Arm. In: Standring S, Ellis H, Healy JC, Johnson D, Williams A, Collins P. editors. Gray's Anatomy. 39th Ed. Philadelphia, Elsevier Churchill Livingstone. 856-857.

3. Kian K, Shapiro JA, Salman L, Khan RA, Merrill D, Garcia L, Eid N, Asif A, Aldahan A, Beathard G. 2011. High brachial artery bifurcation: Clinical considerations and practical implications for an arteriovenous access. Semin Dial. 25:244-247. doi: 10.1111/j.1525-139X.2011.00964.x. Epub Sep 19.

4. Krstonosic B, Srdic B, Maric D, Gudovic R, Mijatov S, Babovic SS. 2010. An anatomical study of double brachial arteries: A case report. Int J Anat Variations. 3:6-8.

5. Okoro IO, Jiburum BC. 2003. Rare high origin of the radial artery: A bilateral, symmetrical case. The Nigerian J Sur Res. 5:70-72.

6. Pokhrel R, Bhatnagar R. 2013. Unilateral high bifurcation of brachial artery. OA Anat. 1(4):34.

7. Pundge S, Wadekar P, Gangane S, Sukre S. 2014. Branching pattern of brachial artery: A morphological study. Int J Healthcare Biomed Res. 2:90-99.

8. Satyanarayana N, Sunitha P, Shaik MM, Devi PSV. 2010. Brachial artery with high up division with its embryological basis and clinical significance. Inter J Anat Variations. 3:56-58.

9. Shewale SN, Sukre SB, Diwan CV. 2012. Bifurcation of brachial artery at its commencement - A case report. Biomed Res. 23:453-456.

10. Varlekar P, Chavda H, Kubavat D, Nagar S, Saiyad SS, Lakhani C. 2013. Higher bifurcation of brachial artery with superficial course of radial artery in forearm: A study report. Int J Med Sci Pub Health. 2:703-706. 